\title{
PATRIMÔNIO IMATERIAL E PAISAGEM CULTURAL CAFEEIRA NA COLÔMBIA
}

ALEJANDRO ESCOBAR HOYOS, UNIVERSIDADE FEDERAL DO RIO GRANDE DO NORTE, NATAL, RIO GRANDE DO NORTE, BRASIL

Licenciado em Comunicação pela Universidad Tecnológica de Pereira (UTP), na Colômbia. Mestrado em Antropologia Social pela Universidade Federal do Rio Grande do Norte (PPGAS-UFRN), Natal, Rio Grande do Norte, Brasil.

E-mail: alescobar@utp.edu.co

DOI

RECEBIDO

http://doi.org/10.11606/issn.1980-4466.v15i29p219-234

$16 / 03 / 2020$

APROVADO

NOTA DO EDITOR: relato publicado na seção Notícias e Depoimentos.

$16 / 04 / 2020$ 


\section{PATRIMÔNIO IMATERIAL E PAISAGEM CULTURAL CAFEEIRA NA COLÔMBIA \\ ALEJANDRO ESCOBAR HOYOS}

\section{RESUMO}

O seguinte artigo mostra algumas contradições do patrimônio imaterial e paisagem cultural cafeeira na Colômbia e como elas refletem nos camponeses e agricultores que vivem do plantio de café. Esta discussão também faz parte de um projeto de mestrado no Programa de Antropologia Social (PPGAS), na Universidade Federal do Rio Grande do Norte (UFRN).

\section{PALAVRAS-CHAVE}

Paisagem cultural. Deslocados internos. Cafeicultura. 


\section{THE CULTURAL LANDSCAPE OF COFFEE IN}

\section{IMMATERIAL HERITAGE}

\section{IN COLOMBIA}

ALEJANDRO ESCOBAR HOYOS

\section{ABSTRACT}

This article shows some contradictions of the immaterial heritage and cultural landscape of coffee in Colombia and how they reflect on peasants and farmers who live from coffee plantation. This study is part of a master's project in the Social Anthropology Program (PPGAS) at Federal University of Rio Grande do Norte (UFRN).

\section{KEYWORDS}

Cultural landscap. Displaced people. Coffee-growing. 


\section{CONTEXTO}

A Colômbia nos mostra como um povo que viveu uma guerra interna, violência e deslocamentos internos segue adiante. Em 1960 foram criados vários grupos armados ou guerrilhas, como as Forças Armadas Revolucionárias da Colômbia - Exército do Povo (FARC-EP), o Exército de Libertação Nacional (ELN) e o Exército Popular de Libertação (EPL), que se opunham às políticas governamentais e aos projetos do Estado. O panorama do confronto armado piorou nas décadas seguintes ao surgimento de grupos paramilitares de extrema direita, vinculados também aos cartéis do narcotráfico. Houve várias etapas de brutalidade, em especial nos anos 1980, quando os grupos subversivos centraram seus ataques na população civil, graças ao financiamento das atividades derivadas do narcotráfico.

Entre 2012 e 2016 estabeleceu-se o diálogo do governo da Colômbia com as FARC-EP e houve uma diminuição da violência e um alívio humanitário em muitas zonas do país que tinham presença histórica e eram controladas pelo grupo armado. Mas depois de afirmar acordo de paz em novembro de 2016, o que se viu foi uma deterioração da situação humanitária, com a reaparição dos deslocamentos internos massivos, assassinatos de líderes sociais, comunitários, ativistas ambientalistas e defensores de direitos. Entre $1^{\circ}$ de janeiro de 2016 e julho de 2020, 971 líderes sociais e defensores de direitos humanos e ex-combatentes das FARC-EP foram assassinados no território 
nacional colombiano (UNIDAD INVESTIGATIVA DE INDEPAZ, p.1, 2020). De acordo com a Unidade para a Atenção e Reparação Integral às Vítimas (UNIDAD DE VÍCTIMAS, 2019), o conflito histórico deixou, até setembro de 2018, mais de 8 milhões de pessoas deslocadas, sendo o país com mais deslocados internos no mundo.

Antes da assinatura dos acordos de paz, desde 2006, o governo nacional tinha implementado diferentes programas e iniciativas para garantir a restituição de terras para a população deslocada que já somava milhões de camponeses, negros e indígenas. No município de El Cairo, no estado do Vale do Cauca, por exemplo, ocorreu um interessante processo de recampesinisação que já tem dez anos e que foi implementado com grupos de famílias deslocadas forçadamente de diferentes estados da Colômbia. Essa experiência é uma das iniciativas que, apesar dos seus inconvenientes, é bem-sucedida.

\section{PATRIMÔNIO IMATERIAL: PAISAGEM CULTURAL CAFEEIRA}

Em 2011 a paisagem cultural cafeeira foi declarada patrimônio imaterial pela Organização das Nações Unidas para a Educação, a Ciência e a Cultura (Unesco) com o objetivo de proteger e salvaguardar o conhecimento tradicional que envolve as pessoas com os plantios de café. Fazem parte do patrimônio imaterial 4 estados e 47 municípios, entre eles o município de El Cairo, no estado do Vale do Cauca (Figura 1).

FIGURA 1

Fazenda tradicional cafeeira, arquitetura e mistura do plantio com a mata nativa.

Fonte: Paisaje

Cultural Cafetero (2011)

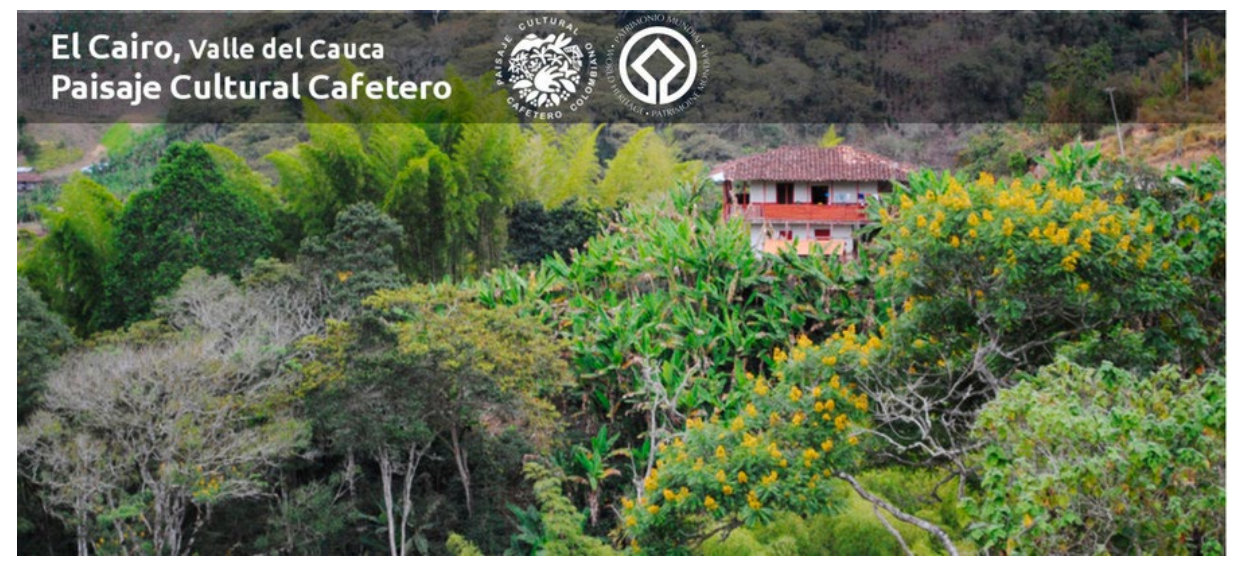


Porém, o reconhecimento desse patrimônio imaterial gera várias questões. O texto "Le patrimoine immatériel entre ambiguïtés et overdose", de Chistian Bromberger (2014), ajuda a aprofundar e entender melhor essas controvérsias ao listar exemplos de patrimônios para a Unesco em que parece haver uma ambiguidade entre o material e o imaterial. Bromberger (2014, p. 3) diz:

Existem expressões materiais da cultura, não uma cultura material que se oponha a uma cultura intangível. Objetos foram corretamente definidos como pensamento solidificado, e Mary Douglas e Baron Isherwood (1980) também diz corretamente que os objetos tornam visíveis as categorias de cultura.

No caso do patrimônio na Colômbia, o objetivo é proteger o conhecimento tradicional e a relação das pessoas com o plantio do café, como também o café como identidade não só de uma região, mas de todo país; mas quando se olha com detalhe, não há essa dita proteção (Figura 2). A substituição do conhecimento tradicional do plantio do café por técnicas de produção de grande escala ligadas ao modelo capitalista do agronegócio tem aumentado há décadas. Na época atual, o plantio tradicional do café, misturado com outros plantios, como da banana, mandioca ou milho, e com uso de adubo orgânico, não são uma prioridade: o que se pode encontrar é o contrário, o monocultivo do café com alto emprego de produtos químicos. É uma questão de ambiguidade, segundo o comitê colombiano do patrimônio cultural cafeeiro, que diz que:

O reconhecimento implica um compromisso de todas as nações pela proteção da paisagem cafeeira; por isto, a declaração implica um compromisso do Estado colombiano junto com a comunidade internacional, e também uma oportunidade para que seus habitantes e visitantes conheçam a paisagem e se involucrem em sua preservação (MINISTÉRIO DE CULTURA DE COLÔMBIA, p.22, 2011, tradução nossa) 
FIGURA 2

Fazenda de café

no Cairo. Fonte: Governo do Estado

Vale do Cauca

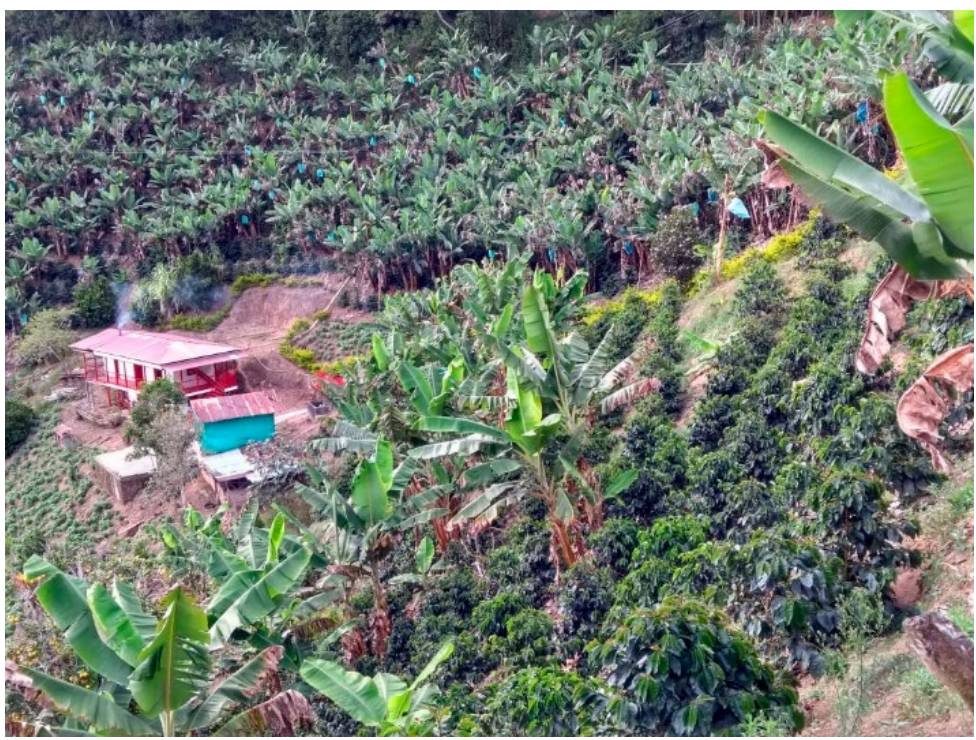

Aqui se entra em um ponto-chave do patrimônio colombiano, e se percebe sua intenção de fomentar o turismo na região. O texto "L'oubli et le retour", de Gaetano Ciarcia (2013), é um grande exemplo das ambiguidades presentes nas declaratórias do patrimônio. $\mathrm{O}$ autor narra como foi o processo de pesquisa no Benin; e sobre o projeto de rota intercontinental da Rota dos Escravos, o autor diz:

"este projeto teve como objetivos principais: a identificação, restauração e promoção de edifícios e locais de memória pertencentes à história da escravidão, a fim de melhorar o desenvolvimento econômico do turismo cultural" (CIARCIA, 2013, p.4).

Porém, é delicado falar da história da escravidão e sua relação com o turismo. $\mathrm{O}$ mesmo autor conta que:

Em outubro de 2005, no começo de minhas investigações no Benin, durante uma entrevista com um notável de Ouidah, fiquei impressionado com uma fórmula hermética e paradoxal repetida pelo menos duas vezes: “esquecendo, sim; perdão, não". Essa formulação foi feita por uma personalidade de origem iorubá, ou seja, de uma comunidade minoritária em Ouidah, cuja maioria dos membros é descendente de ex-escravos, não apenas escravos deportados para a América, mas também escravos empregados no local até o início do século XX em casas e em plantações de óleo de palma (CIARCIA, 2013, p.6, tradução nossa). 
O circuito do memorial consiste em seis etapas principais. Uma delas passa pela árvore do esquecimento ou árvore do retorno, a qual virou parte do ritual pelo qual passavam os escravizados antes de saírem do continente e que na atualidade são pontos de interesses turísticos, mas para uma parte da população são temas de conflito; "esquecimento, sim; perdão, não".

Como sabemos, o tema da escravidão é delicado. $\mathrm{O}$ artigo tem fotos das representações teatrais do sofrimento da escravidão encenadas para os turistas, em maioria, estrangeiros de países como Estados Unidos, os quais queriam se conectar com seus passados, mas não sabemos se estas representações teatrais são a melhor forma de estabelecer tais conexões; 0 artigo também nos fala dos problemas que aconteceram quando pessoas que não fazem parte da comunidade se aproveitaram e construíram hotéis e restaurantes para os turistas.

Voltando à Colômbia, um dos grandes problemas que aconteceram depois da declaratória do patrimônio foi a massificação do turismo na região, sem ter em conta a estrutura e os protocolos adequados para o desenvolvimento do turismo de forma responsável. A maioria dos projetos, como rede hoteleira, restaurantes, parques temáticos, operadoras turísticas, é de pessoas de fora, cujo objetivo é comercial, e não a preservação da identidade e das tradições envolvidas com o café.

Um dos projetos que a organização do patrimônio desenvolve é a "Ruta del café"1, uma campanha que busca promover a zona a nível nacional e internacional. Aqui encontramos uma ambiguidade grande ao perceber que esta rota só tem empreendimentos de pessoas de classe alta ou até estrangeiros, cuja maioria criou cafeterias para atender ao turista ou a outros empreendimentos. Por exemplo, são recorrentes fazendas temáticas que apresentam ao turista o processo do café. No site oficial da paisagem cultural cafeeira, não se encontra um só empreendimento de camponeses que tenham vivido toda sua vida dos plantios do café, que na atualidade quer desenvolver projetos de turismo e gerar um alguma renda para melhorar as condições de vida. É um tema delicado, porque hoje em dia a maioria dos camponeses está deixando de plantar café devido aos preços que não cobrem os gastos necessários para o cultivo. Outro problema foi não terem regulado as visitas aos lugares de reservas ecológicas, ocorrendo a deterioração de vários ecossistemas e zonas de reserva (Figura 3).

1 Ver: https://rutasdelpaisajeculturalcafetero.com 


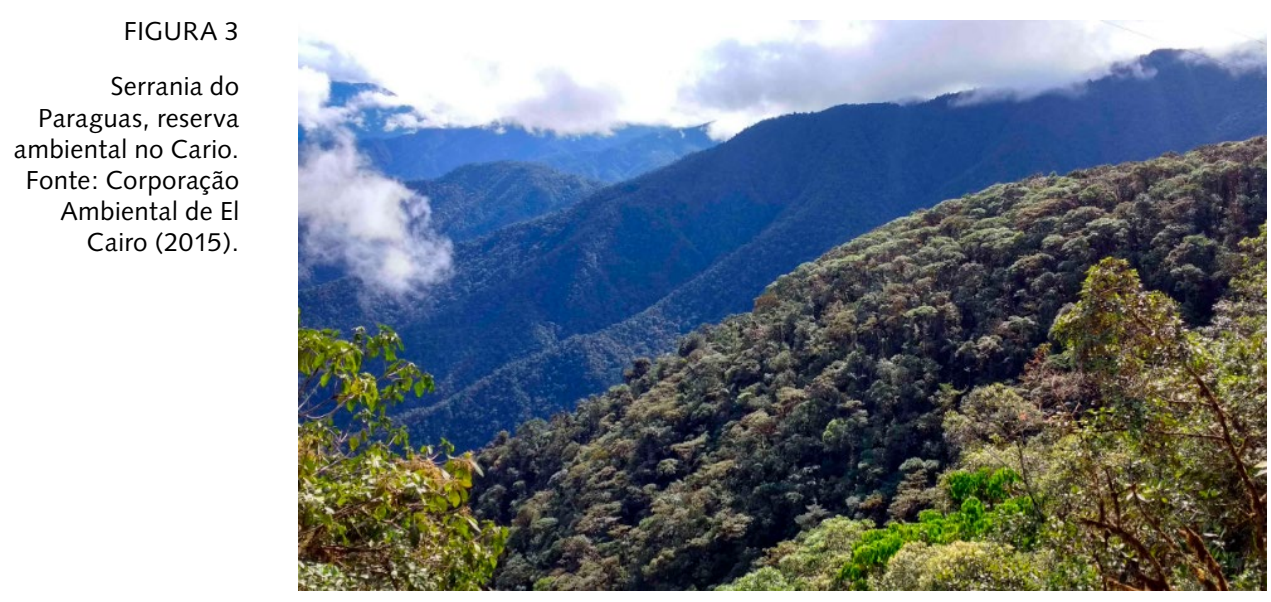

O processo para obter este reconhecimento foi conformado por arquitetos, antropólogos, economistas, historiadores e profissionais das ciências ambientais para atingir os requerimentos da Unesco para dita declaratória. Segundo a organização do patrimônio cafeeiro os profissionais iam:

Selecionar a área mais representativa dos valores culturais da região para identificar percepções das pessoas sobre seu patrimônio cultural. A tradição cafeeira é o símbolo mais representativo da cultura nacional colombiana, pela qual o país obteve reconhecimento mundial. A cultura cafeeira já levou a ricas manifestações materiais e imateriais que incluem a música, a gastronomia, a arquitetura e a cultura (MINISTÉRIO DE CULTURA DE COLÔMBIA, p.22, 2011, tradução nossa)

Em grande parte do território colombiano vê-se a presença do cultivo do café, mas foi na região central dos estados do Quindío, Caldas, Risaralda e Vale do Cauca que um grupo de especialistas e acadêmicos se reuniu com a ideia de apresentar a proposta para a Unesco.

Carlos Castano, professor de meio ambiente e camponês, falou sobre o que representa uma cultura cafeeira, em relação às casas, à comida, vestimenta e sobre sua relação com a agricultura do café e seu manejo, embora nos documentos oficiais do Ministério da Cultura e da organização Paisaje Cultural Cafetero de Colombia se encontre pouca informação, por exemplo, sobre a gastronomia e a arquitetura. Há de fato um aumento da atividade turística nesses municípios, mas foi dito antes, a concentração 
de benefícios entre os empresários ricos gera uma grande ambiguidade no patrimônio cafeeiro.

O comitê do patrimônio cafeeiro elenca os seguintes aspectos que dão conta dos critérios da Unesco para um patrimônio imaterial: café de montanha, predomínio de café, cultivo em ladeira, idade da cafeicultura, patrimônio natural, disponibilidade hídrica, institucionalidade cafeteria, patrimônio arquitetura (Figura 4), patrimônio arqueológico, influência da modernização, patrimônio urbanístico, tradição histórica na produção do café, minifúndio cafeeiro, cultivos múltiplos e formas de produção sustentável do café.

O texto de Bromberger fala da importância de proteger as tradições; em palavras dele:

É perfeitamente legítimo que sejam adotados os meios para preservar essas tradições, esses costumes, essas memórias e que os etnólogos contribuam para investigar os arquivos e se perguntar sobre a "patrimonialização". O que me parece muito mais preocupante é o lugar ocupado, pelo menos na etnologia de nossas próprias sociedades, pelos estudos sobre patrimônio e pela "patrimonologia" (BROMBERGER, 2014, p.8, tradução nossa.)

FIGURA 4

A arquitetura do município do Cairo é uma das melhores conservadas cuidadas na região. Fonte: Corporação

Ambiental de $\mathrm{E}$ Cairo (2014)

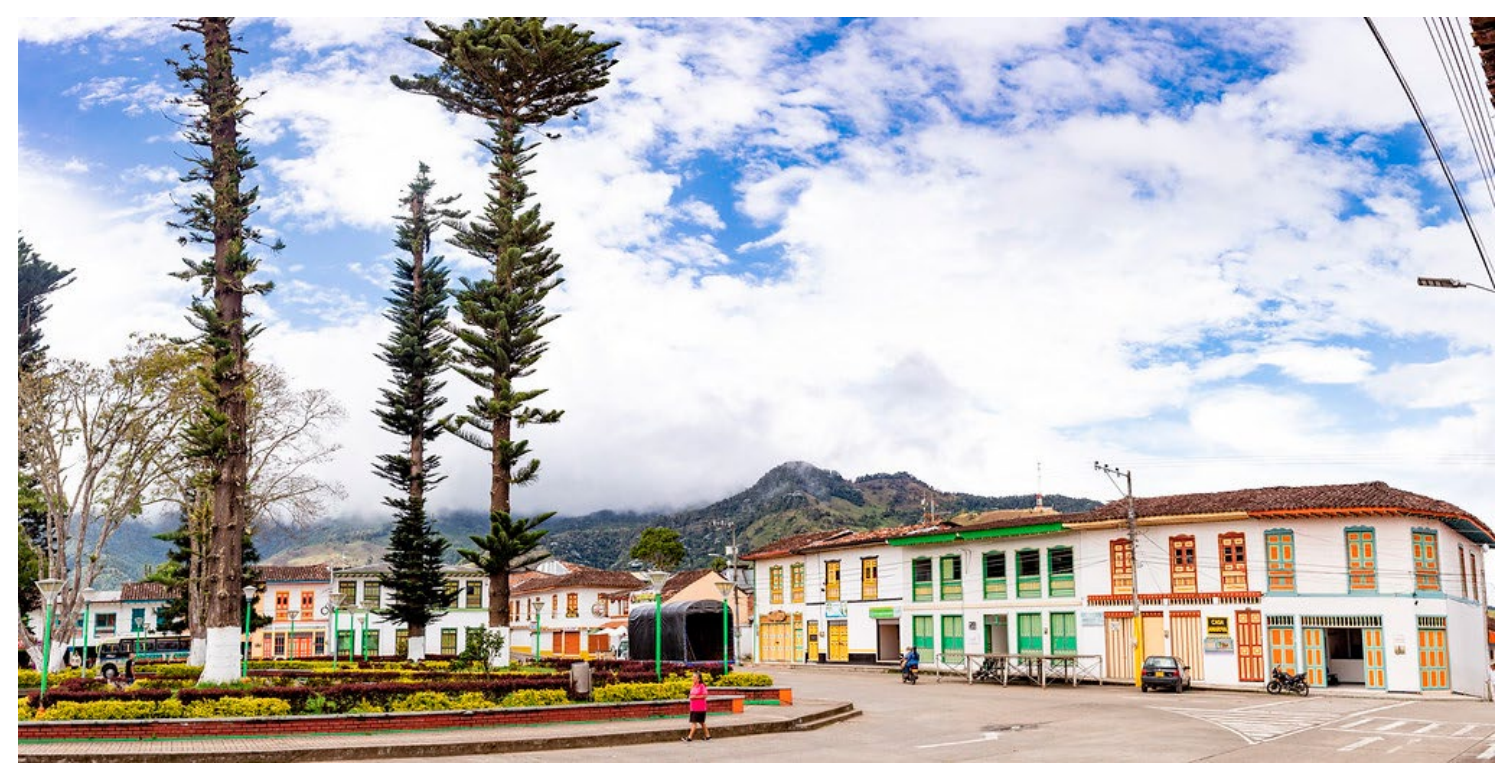


É interessante a reflexão do autor sobre "patrimonologia", já que se percebe dentro dos critérios importantes para o patrimônio cafeeiro outros "patrimônios", como o de arquitetura, natural, arqueológico, urbanístico. É preciso indagar, aprofundar e pesquisar o que quer dizer para o comitê e para outros antropólogos e etnólogos essa "patrimonologia", que pode ser abstrata e difícil de se compreender no contexto da vida cotidiana das pessoas.

O autor Bromberger nos propõe uma reflexão interessante quando diz: "Se os etnologistas têm que contribuir para esse trabalho de salvaguarda e para a história das instituições que o apoiam, eles também têm muito mais a fazer estudando o presente vívido das sociedades" (BROMBERGER, 2014, p. 14) Por isso é de interesse compreender o patrimônio cafeeiro, mas sobretudo entender os conhecimentos tracionais que estão ao redor dos plantios do café, para garantir que não se acabe uma tradição que representa um país inteiro.

\section{A ASSOCIAÇÃO DE DESLOCADOS E O PATRIMÔNIO IMATERIAL PAISAGEM CULTURAL CAFEEIRA}

O município do Cairo apresenta uma situação especial: os fundadores e os seus filhos, junto com uma grande parte da população, foram embora para cidades maiores à procura de outras oportunidades de trabalho e emprego. Dessa forma o município deixa de crescer, sobretudo na área rural, por isso várias associações de deslocados foram enviadas para o município para revitalizar o espaço rural. $\mathrm{Na}$ atualidade o governo do estado, a prefeitura e várias organizações prestam assessoramento técnico e promovem oficinas para ajudar a melhorar a vida dos camponeses e também para assegurar sua permanência no território. Um exemplo é a implantação dos biodigestores, usados para possibilitar o uso do fogão a gás em substituição ao fogão a lenha. Outra organização ambiental, a Serraniagua, faz a conscientização para o cuidado do meio ambiente e promove a agroecologia como bandeira de produção orgânica e amigável com a natureza. Essa organização ambiental promove a produção de café orgânico, que é comprado dos camponeses a preços mais vantajosos e depois torrado e comercializado. Também criou a feira agroecológica e campesina, que ocorre aos finais de semana, para a venda dos produtos feitos na fazenda. 
Como é narrado no livro de criação coletiva Echando raíces en $\mathrm{El}$ Cairo (2016), está expresso o sentimento dos camponeses acerca da condição de deslocamento:

Vemos de municípios fortemente afetados por o conflito armado Colombiano, dos estados de Choco, Huila, Cauca, Quindío, Caquetá, Antioquia, Putumayo, Nariño, Risaralda, Guajira. E por isto que cada um de nós tem diferentes histórias, tradições, costumes e modos de pensar diferente (BARRERA; PADILLA, 2016, p. 8).

Um total de 50 famílias, vindas de 11 estados diferentes, chegaram ao município de El Cairo com a perspectiva da reconstruir suas vidas em um novo território.

O texto "Alimentation et vivre-ensemble: le cas de la créolisation de Laurence Tibère" diz, em relação aos contextos multiculturais "em uma situação multicultural, a manipulação - no sentido neutro do termo - de símbolos ocupa um lugar central na expressão de identidades e na gestão social da convivência" (TIBÈRE, 2013, p. 7, tradução nossa). É de interesse entender como é a convivência e a relação entre famílias, sabendo que são famílias de diferentes estados e, por conseguinte, com diferentes identidades.

$\mathrm{O}$ texto de Tibère traça mais questões a respeito da alimentação e da culinária, por isso se pode perceber como pessoas de diferentes regiões ou estados da Colômbia adquirem hábitos comuns em relação à comida. O autor diz:

As populações exiladas são assim reenraizadas no solo da reunião; adquiriram uma linguagem, adotaram estilos de vida e um modelo alimentar que articula componentes comuns (cozinha crioula) e universos que, embora na maioria das vezes sejam crioulos, são específicos (TIBÈRE, 2013, p. 4, tradução nossa)

O texto apresenta questões muito interessantes que antes não tinham sido percebidas; a cozinha crioula tem um papel importante para se compreender essa mistura de culturas ou multiculturas e como se desenvolve um novo território a partir da alimentação ou comida tradicional, este e um ponto chave para pensar o patrimônio paisagem cultural cafeeiro, no caso do Cairo uma mistura de pessoas de diferentes regiões criam um território multicultural onde se pode encontrar essa diversidade na alimentação cotidiana das pessoas (Figura 5). 


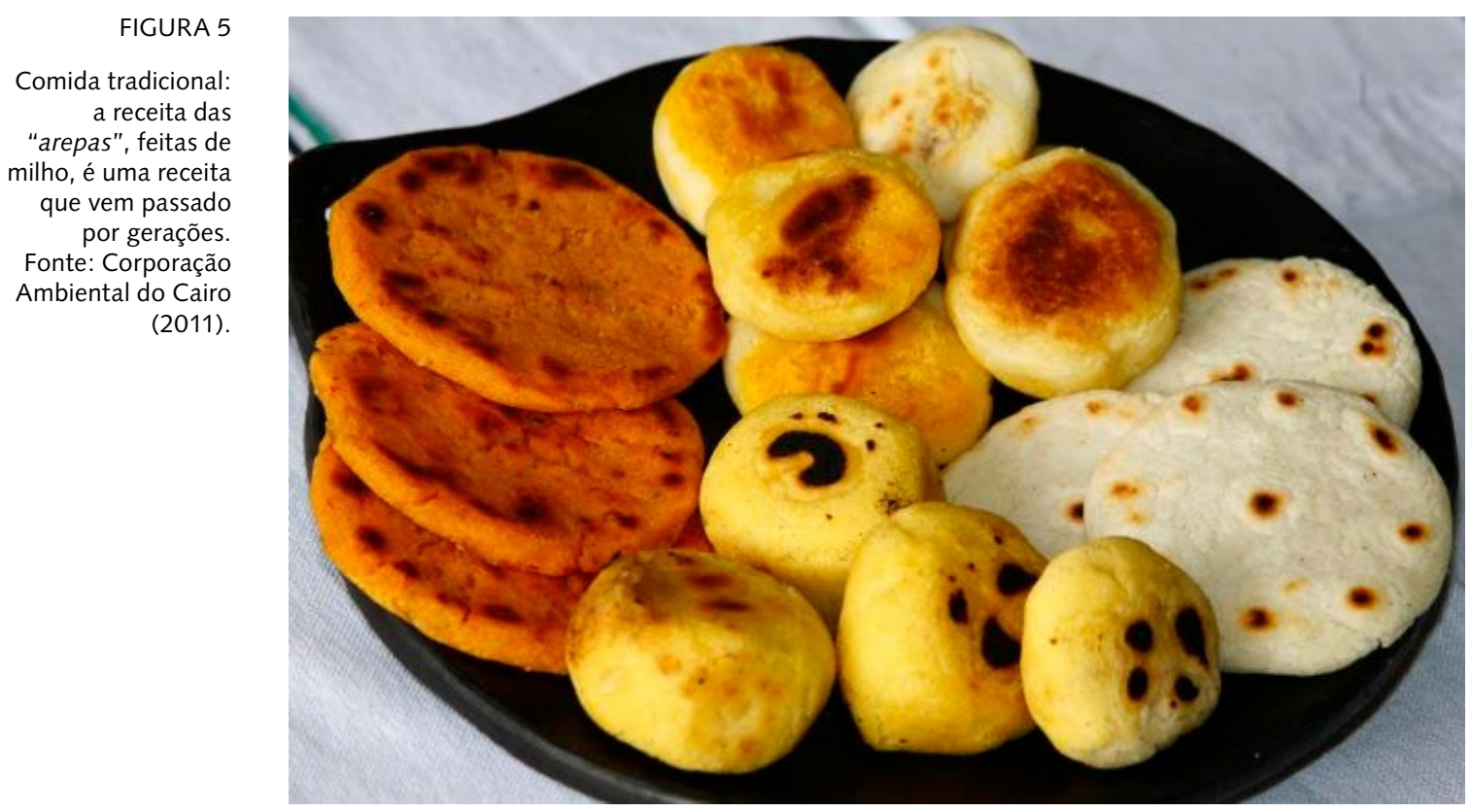

O patrimônio paisagem cultural cafeeira está divido em várias zonas. A zona $\mathrm{F}$ corresponde às localizações rurais da cordilheira ocidental dos municípios de Águila e El Cairo, no estado do Vale de Cauca. Incluem além as áreas urbanas do Cairo. O centro histórico urbano está declarado bem de interesse cultural; apresenta um alto nível de homogeneidade na arquitetura e uma manifestação direta da principal atividade econômica que desenvolveu a produção cafeteria.

El Cairo é um tesouro entre as nuvens: a 1.850 metros sobre o nível do mar, é uns dos municípios mais jovens do estado do Vale do Cauca (Figura 6). Fundado em 1920, a história do município inicia-se com a colonização do estado de Antioquia. Um grupo de colonos vindo do Norte instalou-se nessa região para cultivar a terra. Desde então, a economia municipal se centrou na produção do café, que se mistura ainda ao cultivo da banana, mandioca, feijão, abacate e tomate. 


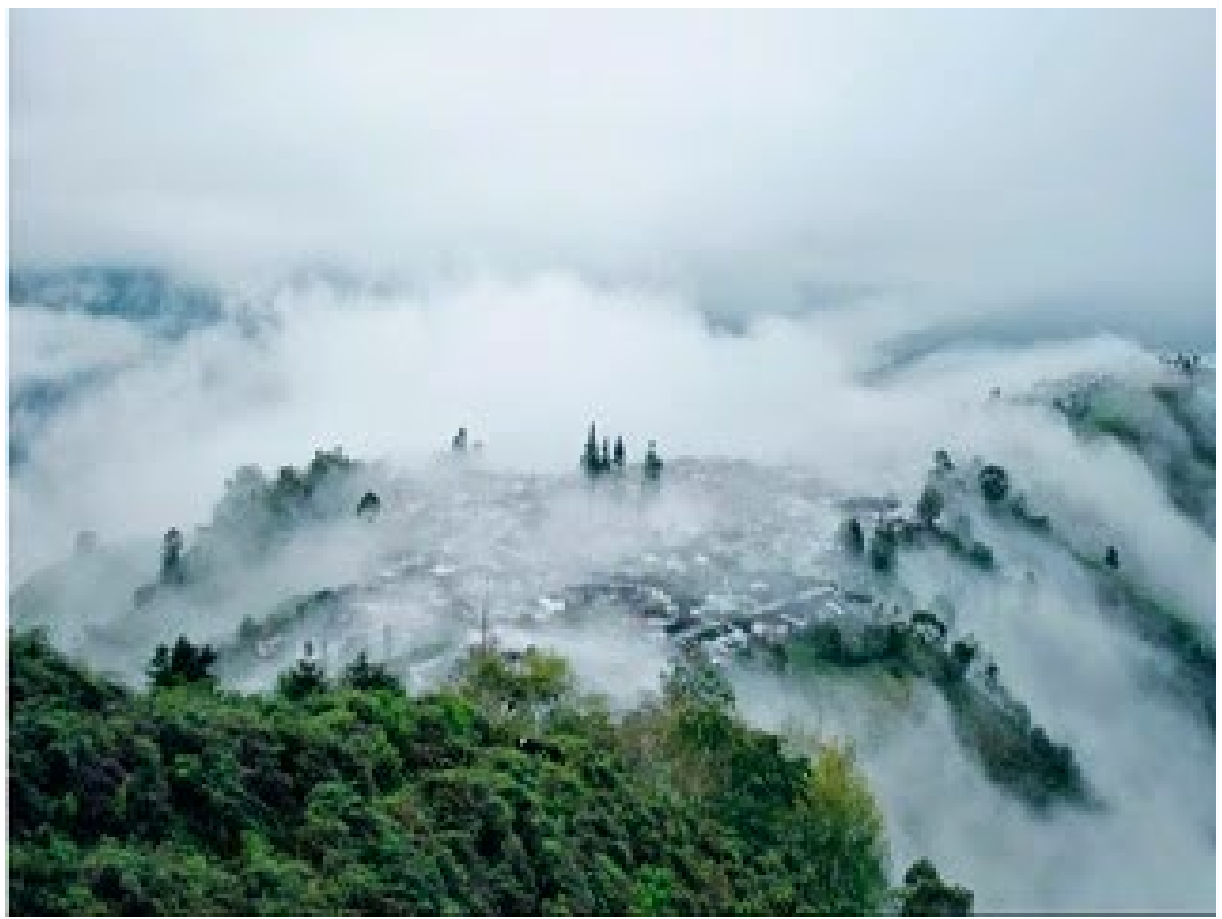

Novamente Tibère traça questões de interesse aspecto sobre a colonização quando diz:

A crioulização resulta dos processos de aculturação ocorridos em certas sociedades colonizadas, nas quais o sistema de produção e a organização socioeconômica permitiram, em uma estrutura sócio-racial desigual, hierárquica e tensa, estreitar contatos entre populações de diferentes culturas. Esses contatos favoreceram hibridizações e reformulações culturais e deram origem a linguagens, sistemas de crenças, formas estéticas, cozinhas, novas e criadas. (TIBÈRE, 2013, p. 9, tradução nossa)

É o caso da Reunião, e bem diferente do caso de El Cairo, mas a colonização do estado de Antioquia deixa muitas influências na região, por exemplo, o café. Mas também não se pode esquecer das hibridizações em relação aos indígenas e negros que fazem parte da região e que tiveram da mesma maneira influência na comida e na cozinha do município.

El Cairo é reconhecido na região do norte do Vale por suas frequentes atividades de entretenimento e turismo. Ao longo do ano se celebram no 
município as festas do retorno, da semana cívica, do camponês, dos cachacos, entre outras. Além de sua privilegiada posição na apreciada "Serranía dos Paraguas", onde se permite oferecer canopying, trilhas e observação de flora e fauna em um ecossistema de bosques naturais e santuários ecológicos que, conservam sua beleza natural. Por fim, o município de El Cairo apresenta uma combinação entre arquitetura colonial e natureza de grande magnitude. É um município típico cafeeiro, com pessoas amáveis e seviciais que procura potencializar o turismo cultural cafeeiro, ambiental e gastronômico.

\section{CONCLUSÃO}

A valorização patrimônio imaterial colombiano é muito importante para salvaguardar os conhecimentos tracionais em relação à cultura cafeeira e a tudo o que está ao redor dessa cultura, como a arquitetura e a gastronomia. É uma região de identificação dos habitantes com agricultura cafeeira, mesmo entre os habitantes do município de El Cairo oriundos de outras regiões se apropriaram do local e adotaram a cultura do café.

O café dá sustento a milhares de famílias, mas também traz consigo uma carga cultural, de identidade e de herança grande. Para apoiar os processos de volta ao campo dos deslocados internos se vem apresentando diferentes projetos que assegurem a vida destas comunidades na zona rural. Um deles é o turismo apoiado na declaratória da paisagem cultural cafeeira, que tem atraído muitas pessoas à região. Encaminhar estes turistas para que conheçam as particularidades da vida dos camponeses e sua relação com a terra e o café será de muita ajuda para estas famílias que, além de compartilhar suas experiências e conhecimentos, obtém retorno financeiro extra para sobreviver quando a produção da agricultura não se mostra suficiente ao sustento.

\section{REFERÊNCIAS}

BARRERA, Pedro; PADILLA, Andrea. Echando raíces en El Cairo: experiencias de reconciliación y construcción de paz desde una comunidad campesina reubicada. Bogotá: Pontificia Universidad Javeriana, 2016. Disponível em: http://www.sjrcolombia.org/web/wp-content/ uploads/2013/o6/Cartilla-Final-Con-Portada_V.Lectura.pdf. Acesso em: 11 jul. 2020.

BROMBERGER, Christian. "Le patrimoine immatériel” entre ambiguïtés et overdose. L'Homme, Paris, n. 209, p. 143-151, 2014. DOI: https://doi.org/10.40oo/lhomme.23513 
CIARCIA, Gaetano. L'oubli et le retour: figures d'une épopée mémorielle sur la Route de l'Esclave au Bénin. L'Homme, Paris, n. 206, p. 89-119, 2013. DOI: https://doi.org/10.400o/ lhomme. 24518

MINISTÉRIO DE CULTURA DE COLÔMBIA. Paisaje cultural cafetero: un paisaje cultural productivo en permanente desarrollo. Bogotá, 2011.

ORGANIZACIÓNN AMBIENTAL SERRANIAGUA, 2016. Disponível em: https://www. serraniagua.org/inicio. Acesso em: 17 fev. 2020.

PAISAJE CULTURAL CAFETERO. Patrimonio mundial, 20I7. Disponível em: http://paisajeculturalcafetero.org.co/. Acesso em: 17 fev. 2020.

TIBÈRE, Laurence. Alimentation et vivre-ensemble: le cas de la créolisation. Anthropologie et Sociétés, Québec, v. 37, n. 2, p. 27-43, 2013. DOI: https://doi.org/10.7202/1017904ar

UNIDAD DE VÍCTIMAS. Registro Único. Unidad de victimas. Obtenido de Red Nacional de Información. Disponível em: https://rni. unidadvictimas. gov. co/RUV, 2019.

UNIDAD INVESTIGATIVA DE INDEPAZ. Registro de lideres y personas defensoras de DDHH asesinadas desde la firma del acuerdo de paz del 24/11/2016 al 15/07/2020. Informe Especial, Bogotá, 15 de julio 2020.

\section{(cc) EY-Wo-sh}

